\title{
NORMAS DE PUBLICAÇÃO DA REVISTA ELETRÔNICA DEBATES EM EDUCAÇÃO CIENTÍFICA E TECNOLÓGICA
}

\author{
Editores: \\ Sidnei Quezada Meireles Leite, Antônio Donizetti Sgarbi \\ Carlos Roberto Pires Campos, Hélio Rosetti Júnior
}
Programa de Pós-graduação em Educação em Ciências e Matemática
Instituto Federal do Espírito Santo
Publicado em Junho de 2013

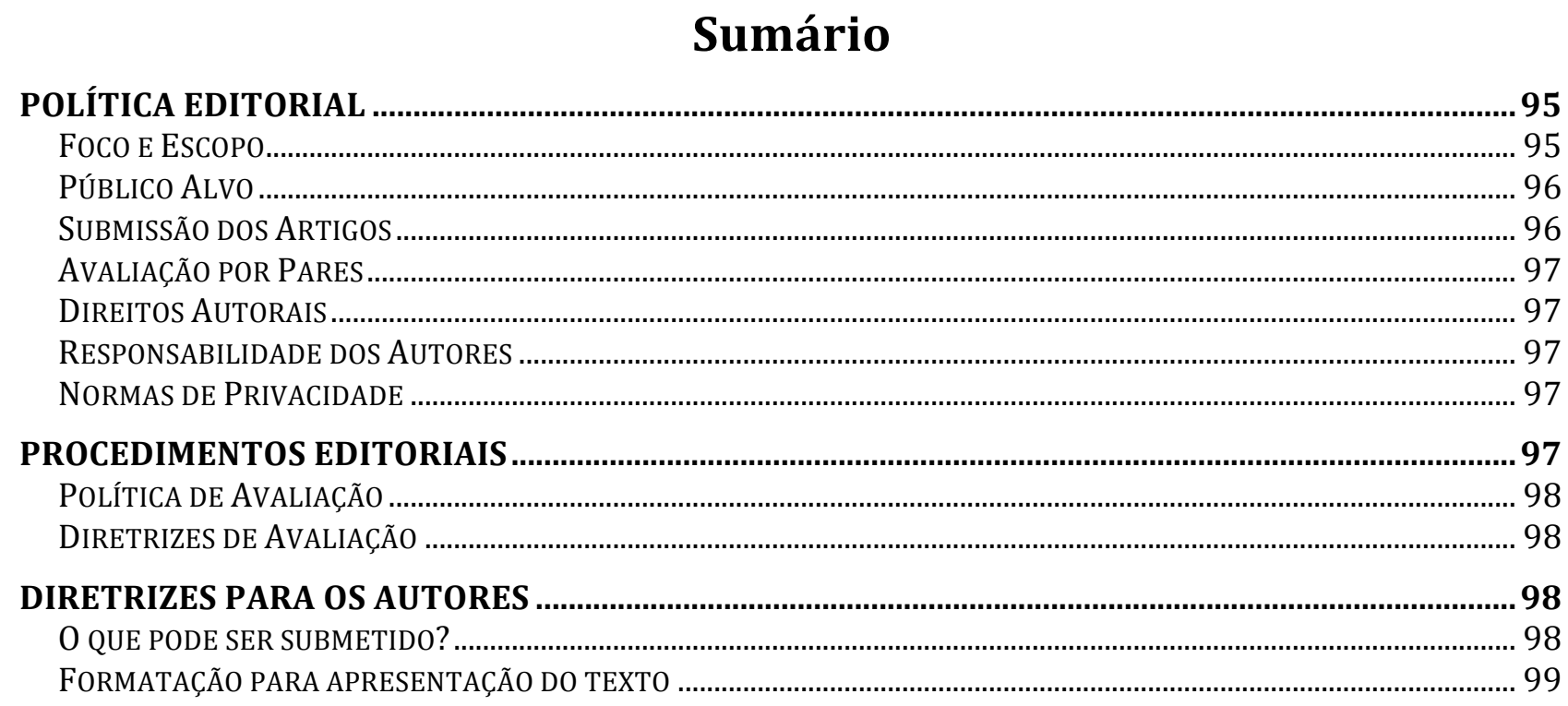

\section{POLÍTICA EDITORIAL}

\section{FOCO E ESCOPO}

A Revista Eletrônica Debates em Educação Científica e Tecnológica (Revista DECT) - ISSN 2236-2150 - é um periódico semestral (Junho e Dezembro) vinculado ao Programa de Pósgraduação em Educação em Ciências e Matemática do Instituto Federal do Espírito Santo. Há uma versão anual impressa deste periódico, denominada Debates em Educação Científica $\boldsymbol{e}$ Tecnológica, ISSN 2179-6955 quando reunimos alguns dos artigos de maior destaque no ano vigente. A versão eletrônica poderá ter números extras durante o ano, conforme a demanda de artigos e decisão do Comitê Executivo e Comitê Científico.

A Revista Eletrônica DECT é organizada em cinco linhas temáticas norteadas pelo texto central - Educação Científica e Tecnológica. Cada número da revista poderá abordar uma ou mais linhas temáticas, conforme a demanda de artigos aceitos e decisão do Comitê Editorial, a saber: 
a) Ensino de Ciências e Matemática. Este tema reúne os estudos que tratam das políticas educacionais, do currículo, das práticas pedagógicas e das metodologias de ensino no contexto do Ensino de Ciências e Matemática.

b) Formação Inicial e Continuada de Professores da Educação Básica. Este tema reúne os estudos que tratam das políticas educacionais, do currículo, das práticas pedagógicas, das representações sociais no contexto da formação inicial e continuada de professores.

c) Tecnologias Educacionais e Recursos Didáticos. Este tema reúne estudos que tratam dos recursos didáticos, das tecnologias educacionais e do uso dos ambientes virtuais de aprendizagem no contexto das tecnologia educacionais.

d) Educação Profissional. Neste tema concentram-se os estudos que tratam da educação profissional nas diferentes modalidades e nas diferentes etapas educacionais (educação infantil, educação básica e educação superior).

e) Diversidade e Inclusão Social. Neste tema concentram-se os estudos que tratam da ideia ligada aos conceitos de pluralidade, multiplicidade, diferentes ângulos de visão e de abordagem, heterogeneidade e variedade. Neste item estão inclusos as questões culturais, educação de jovens e adultos, direito humano, diversidade sexual, biodiversidade, psicologia, e do discurso presente na difusão do conhecimento.

O texto produzido por colaboradores nacionais ou internacionais deve ter um caráter científico, inédito e original, podendo ser escrito em português e espanhol, será publicado após revisão por pares e aprovação. 0 projeto da Revista Eletrônica DECT foi construído com uma visão interdisciplinar com o objetivo principal de divulgar estudos científicos realizados no campo da Educação Científica e Tecnológica.

\section{PÚBLICO ALVO}

Pesquisadores e estudantes de graduação e pós-graduação, bem como o público em geral com estudos e/ou pesquisas nos temas tratados na publicação.

\section{SUBMISSÃO DOS ARTIGOS}

A submissão do manuscrito é exclusivamente eletronicamente no site da Revista Eletrônica DECT:

\section{http://ojs.ifes.edu.br.}

O processo de acompanhamento do andamento da análise e as resposta poderão ser feitas no próprio site e por e-mail. Contatos, quando necessários, poderão ser feitos pelo e-mail: revistadect@gmail.com. No ato da submissão, o autor deverá fazer a seguinte declaração:

* durante a realização da pesquisa, os procedimentos éticos referentes ao trabalho científico foram atendidos;

* o artigo é inédito e não está sendo avaliado por outro periódico;

* no caso de estudo com humanos, foi conduzido com o consentimento de um Comitê de Ética em Pesquisa devidamente registrado no Ministério da Saúde, caso contrário, justificar;

* a responsabilidade pela informações e pelo conteúdo são do(s) autor(es);

* não existe Conflito de Interesses em relação ao material apresentado." 


\section{AVALIAÇÃO POR PARES}

O Comitê Científico (pareceristas/avaliadores) de Revista Eletrônica DECT é formado por profissionais com conhecimento e experiência acadêmica, tendo a atribuição de revisar os artigos com base nesta Norma de Publicação. Os artigos a serem revisados serão previamente selecionados pelo Comitê Executivo e encaminhados a, pelo menos, dois membros do Comitê Científico aos quais caberão a emissão de parecer para o Comitê Executivo.

Caso haja divergência nas avaliações, uma análise adicional deverá ser realizada, por um terceiro membro do Comitê Científico ou Consultor ad hoc, para parecer final. 0 prazo total de análise será de 03 (três) meses. A ordem para a publicação será definida pelo Comitê Executivo e pelo Comitê Científico, segundo critérios de oportunidade e conveniência, desde que o artigo tenha sido aprovado por dois membros revisores.

\section{DIREITOS AUTORAIS}

Os direitos autorais dos artigos são da Revista Eletrônica Debates em Educação Científica e Tecnológica publicados em cada edição (eletrônica ou impressa). Ao submeter o artigo, o autor principal acorda com a Revista Eletrônica DECT a seção de direitos para publicação. É de livre reprodução de qualquer artigo, por quaisquer meios, para fins de educação. Para publicação dos artigos da Revista Eletrônica DECT em outra revista, ou outro meio de divulgação, requer autorização por escrito dos Editores.

\section{RESPONSABILIDADE DOS AUTORES}

Ao submeter o artigo no sistema de gerenciamento da Revista Eletrônica DECT, os autores efetuam a Declaração Eletrônica de Autorização para Publicação.

\section{NORMAS DE PRIVACIDADE}

Os nomes e endereços informados nesta revista serão usados exclusivamente para os serviços prestados por esta publicação, não sendo disponibilizados para outras finalidades ou a terceiros.

\section{PROCEDIMENTOS EDITORIAIS}

Após submeter o texto através do sistema online (http://ojs.ifes.edu.br), a confirmação do recebimento e registro será enviada ao autor, automaticamente por e-mail pelo sistema, ao fim do registro de submissão. Se o texto estiver de acordo com as normas de formatação (item 3 e subsequentes), será analisado pelo Comitê Executivo que dará início ao processo de avaliação, encaminhando a 2 (dois) pareceristas membros do Comitê Científico, ou para consultores ad hoc, em casos extraordinários.

Os Pareceristas são escolhidos pelo Comitê Executor, entre pesquisadores de reconhecida competência acadêmica. Os Pareceristas e/ou Consultores ad hoc, após análise do texto, poderão opinar pela: recomendação, recomendação com restrições e não recomendação. Ao final do processo, o Autor receberá cópia dos pareceres dos Pareceristas/Consultores. Em caso de não recomendação, o Autor poderá submetê-lo novamente depois de cuidadosa revisão. 
Em caso de recomendação com restrições, o autor poderá apresentar em 30 (trinta) dias a versão reformulada do texto para reapreciação, acompanhada de texto no mensagem do sistema de gerenciamento da revista, informando as modificações efetuadas e justificando as não realizadas. O Comitê Executivo pode rejeitar as alterações e sugerir modificações (quantas vezes forem necessárias) ou indicar o texto reformulado para publicação.

0 texto aceito será encaminhado para elaboração da Prova (*.pdf) e enviado ao autor para que seja conferida e devolvida com possíveis correções (exceto no título ou no nome do(s) autor(es)), no prazo de 3 (três) dias. A não devolução, no prazo estipulado, implicará na concordância do autor. A decisão final sobre a publicação de um texto cabe ao Comitê Executivo, auxiliados pelos pareceres. 0 autor será comunicado sobre o resultado final da avaliação, por e-mail, indicando a previsão da publicação.

\section{POLÍTICA DE AVALIACÃ̃O}

O manuscrito pode ser submetido a qualquer tempo (fluxo contínuo). Entretanto, caso sejam encaminhados até as datas abaixo, pode vir a ser publicado no fascículo com fechamento no prazo estabelecido, a saber:

30 de Março para o volume com fechamento em 30 de Junho;

$\checkmark 30$ de Setembro para o volume com fechamento em 30 de Dezembro.

O prazo para avaliação varia de 30 a 120 dias úteis, dependendo da natureza do material submetido, complexidade e cumprimento das exigências editorias. 0 prazo mínimo se refere aos materiais: corretamente formatados, que sigam as normas editorias previstas.

\section{DIRETRIZES DE AVALIAÇÃO}

Serão avaliados pelos pareceristas os seguintes quesitos:

* Potencial contribuição para a Educação Científica e Tecnológica;

* Pertinência do trabalho para ser publicado na Revista Eletrônica DECT;

* Estrutura do manuscrito: título, palavras-chave, resumo, abstract, apresentação do problema, metodologia, objetivo, resultados alcançados; figuras, tabelas e/ou outros recursos utilizados (imagem, som ou outros), assim como a adequação das legendas;

* Abordagem teórica e metodológica no manuscrito.

\section{DIRETRIZES PARA OS AUTORES}

\section{O QUE PODE SER SUBMETIDO?}

Serão aceitos para publicação textos científicos produzidos em língua portuguesa ou espanhola com resumo em língua portuguesa ou espanhola - e inglesa (abstract). Serão aceitos os seguintes formatos para publicação:

Artigos científicos (empírico, experimental ou teórico): documento inédito oriundo de pesquisa científica. Os dados devem ser originais e destinados exclusivamente para esta revista, não tendo sido publicado integralmente em nenhum outro veículo. São esperados 
textos com 10 a 25 páginas. Neste item estão incluídas os Artigos de Revisão de Literatura e Resenha

Ensaio: Uma reflexão produzida a partir de um levantamento bibliográfico, produzindo uma discussão acerca de um assunto da área da Educação - focando uma das áreas da Revista DECT. Espera-se textos com mínimo de 5 páginas.

\section{FORMATAÇÃO PARA APRESENTAÇÃO DO TEXTO}

Utilizar folha A4, margens $2,0 \mathrm{~cm}$ (superior, inferior, esquerda e direita), espaçamento simples $(1,0)$. Use itálico em palavras ou expressões a serem enfatizadas e para palavras estrangeiras. Use negrito apenas no título, subtítulos e nomes dos autores. Não use palavras sublinhadas ao longo do texto, nem marcas d'água.

Todo o texto deverá se escrito em letra cursiva (LIVRE ESCOLHA), tamanho 12.

TÍTULO na língua empregada no artigo (português ou espanhol).

TÍTULO EM INGLÊS.

RESUMO (em português ou espanhol, com até 800 caracteres contando espaços. Não deve incluir referências bibliográficas. Deve conter um pequeno texto sobre o assunto aborddo no artigo.

PALAVRAS-CHAVE (em português ou espanhol). No máximo 5, letras minúsculas, separadas por ponto. Veja nos bancos de dados as palavras-chave corretas.

ABSTRACT (em inglês). Deve corresponder ao conteúdo explicitado no Resumo.

KEYWORDS (em inglês). No máximo 5, letras minúsculas, separadas por ponto.

CORPO DO TEXTO. 0 títulos dos itens devem ser escritos em CAIXA ALTA. Espera-se ter os seguintes itens:

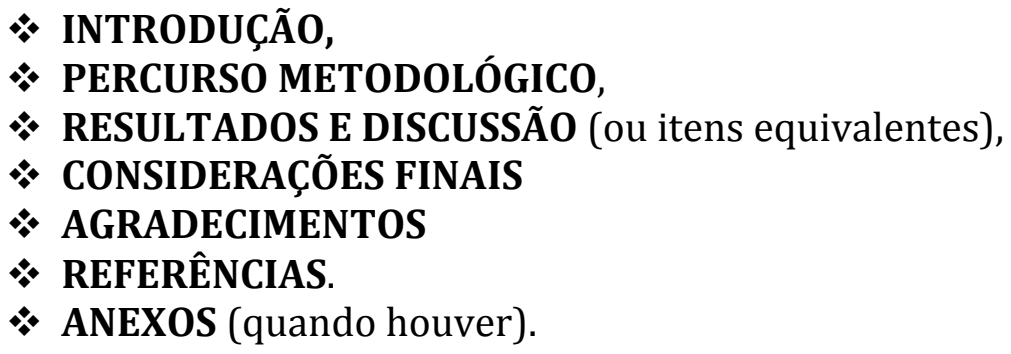

Tabelas, Quadros e Imagens: devem ser incluídas no texto em sequência de sua citação. Legendas acima das tabelas e quadros, tamanho da letra 12, indicado a fonte. As imagens devem apresentar resolução mínima de 300 dpi.

Agradecimentos e créditos a instituições de financiamento deverão aparecer no final do texto e antes do item Referências.

Referências deve seguir as Normas ABNT mais recente.

Notas de rodapé. As notas devem ser listadas abaixo de cada referida página onde foram feitas as indicações em algarismos arábicos - sobrescrito (utilizar o recurso "Inserir Notas..." do Word).

ANEXOS (quando houver). Devem ser indicados no corpo do texto e apresentados no final, após as referências. 